REVIEW SUMMARY

EARTH SYSTEM

\section{Natural, incidental, and engineered nanomaterials and their impacts on the Earth system}

\author{
Michael F. Hochella Jr. *, David W. Mogk, James Ranville, Irving C. Allen, \\ George W. Luther, Linsey C. Marr, B. Peter McGrail, Mitsu Murayama, \\ Nikolla P. Qafoku, Kevin M. Rosso, Nita Sahai, Paul A. Schroeder, \\ Peter Vikesland, Paul Westerhoff, Yi Yang
}

BACKGROUND: Natural nanomaterials have always been abundant during Earth's formation and throughout its evolution over the past 4.54 billion years. Incidental nanomaterials, which arise as a by-product from human activity, have become unintentionally abundant since the beginning of the Industrial Revolution. Nanomaterials can also be engineered to have unusual, tunable properties that can be used to improve products in applications from human health to electronics, and in energy, water, and food production. Engineered nanomaterials are very much a recent phenomenon, not yet a century old, and are just a small mass fraction of the natural and incidental varieties. As with natural and incidental nanomaterials, engineered nanomaterials can have both positive and negative consequences in our environment.
Despite the ubiquity of nanomaterials on Earth, only in the past 20 years or so have their impacts on the Earth system been studied intensively. This is mostly due to a much better understanding of the distinct behavior of materials at the nanoscale and to multiple advances in analytic techniques. This progress continues to expand rapidly as it becomes clear that nanomaterials are relevant from molecular to planetary dimensions and that they operate from the shortest to the longest time scales over the entire Earth system.

ADVANCES: Nanomaterials can be defined as any organic, inorganic, or organometallic material that present chemical, physical, and/or electrical properties that change as a function of the size and shape of the material. This behavior is most often observed in the size range between $1 \mathrm{~nm}$ up to a few to several tens of

\begin{abstract}
Modern Earth, from a nanoperspective. Earth has thousands of terragrams of natural nanomaterials moving around the planet annually. This is now accompanied by 1 to $10 \mathrm{Tg}$ of incidental nanomaterials formed in or delivered to the atmosphere from, for example, factory and transportation emissions, mining, forest fires, and urban processes, as well as less than a terragram annually from engineered nanomaterials that make their way into the environment mostly through wastewater treatment plants, holding ponds, and landfills. All of these, together, affect the entire Earth system.
\end{abstract}

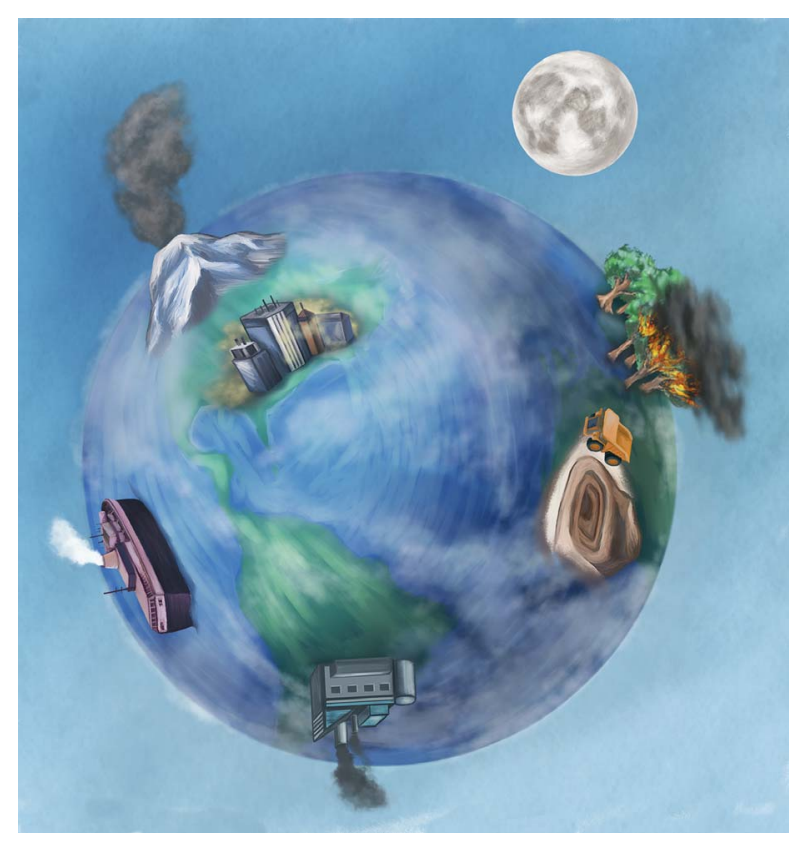

nanometers in at least one dimension. These materials have very high proportions of surface atoms relative to interior ones. Also, they are often subject to property variation as a function of size owing to quantum confinement effects. Nanomaterial growth, dissolution or evaporation, surface reactivity, and aggregation states play key roles in their lifetime, behaviors, and local interactions in both natural and engineered environments, often with global consequences.

It is now possible to recognize and identify critical roles played by nanomaterials in

\section{ON OUR WEBSITE}

Read the full article at http://dx.doi. org/10.1126/ science.aau8299

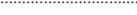

the origin of life and in the early evolution of bacterial cell walls. Also, weathering reactions on the continents produce various bioavailable iron (oxy)hydroxide natural and incidental nanomaterials, which are transported to the oceans via riverine and atmospheric pathways and which influence ocean surface primary productivity and thus the global carbon cycle. A third example involves nanomaterials in the atmosphere that travel locally, regionally, and globally. When inhaled, the smallest nanoparticles can pass through the alveolar membranes of the lungs and directly enter the bloodstream. From there, they enter vital organs, including the brain, with possible deleterious consequences.

OUTLOOK: Earth system nanoscience requires a convergent approach that combines physical, biological, and social sciences, as well as engineering and economic disciplines. This convergence will drive developments for all types of intelligent and anticipatory conceptual models assisted by new analytical techniques and computational simulations.

Ultimately, scientists must learn how to recognize key roles of natural, incidental, and engineered nanomaterials in the complex Earth system, so that this understanding can be included in models of Earth processes and Earth history, as well as in ethical considerations regarding their positive and negative effects on present and predicted future environmental and human health issues.

The list of author affiliations is available in the full article online. *Corresponding author. Email: hochella@vt.edu Cite this article as M. F. Hochella Jr. et al., Science 363, eaau8299 (2019). DOI: 10.1126/science.aau8299

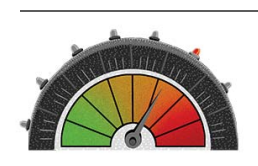

TOMORROW'S EARTH Read more articles online at scim.ag/TomorrowsEarth 
REVIEW

EARTH SYSTEM

\section{Natural, incidental, and engineered nanomaterials and their impacts on the Earth system}

\author{
Michael F. Hochella Jr. ${ }^{1,2 *}$, David W. Mogk ${ }^{3}$, James Ranville ${ }^{4}$, Irving C. Allen ${ }^{5}$, \\ George W. Luther ${ }^{6}$, Linsey C. Marr ${ }^{7}$, B. Peter McGrail ${ }^{8}$, Mitsu Murayama ${ }^{9,10,11}$, \\ Nikolla P. Qafoku' ${ }^{2}$, Kevin M. Rosso ${ }^{12}$, Nita Sahai ${ }^{13}$, Paul A. Schroeder ${ }^{14}$, \\ Peter Vikesland ${ }^{7}$, Paul Westerhoff ${ }^{15}$, Yi Yang ${ }^{16}$
}

Nanomaterials are critical components in the Earth system's past, present, and future characteristics and behavior. They have been present since Earth's origin in great abundance. Life, from the earliest cells to modern humans, has evolved in intimate association with naturally occurring nanomaterials. This synergy began to shift considerably with human industrialization. Particularly since the Industrial Revolution some two-and-a-half centuries ago, incidental nanomaterials (produced unintentionally by human activity) have been continuously produced and distributed worldwide. In some areas, they now rival the amount of naturally occurring nanomaterials. In the past half-century, engineered nanomaterials have been produced in very small amounts relative to the other two types of nanomaterials, but still in large enough quantities to make them a consequential component of the planet. All nanomaterials, regardless of their origin, have distinct chemical and physical properties throughout their size range, clearly setting them apart from their macroscopic equivalents and necessitating careful study. Following major advances in experimental, computational, analytical, and field approaches, it is becoming possible to better assess and understand all types and origins of nanomaterials in the Earth system. It is also now possible to frame their immediate and long-term impact on environmental and human health at local, regional, and global scales.

N atural nanomaterials have always been abundantly present in the 4.54-billionyear-old Earth system. Therefore, ever since life first appeared on this planet, natural nanomaterials and living things have coevolved. Today, both incidental and engineered nanomaterials, together known as anthropogenic nanomaterials (Box 1), have shifted this long-established balance. Incidental nanomaterials have been produced since the dawn of humanity; they can, for example, be created mechanically by striking two rocks together. Engineered nanomaterials have only been produced for less than a century; the earliest products, like Aerosil (fumed silica), were first commercially manufactured in the 1940s, and aqueous production of silica nanospheres dates back to the 1960s (1). Since then, engineered nanomaterials have increased dramatically in variety, complexity, and sophistication (2), but incidental nanomaterials are much more abundant both regionally and globally. Incidental nanomaterials may even rival natural nanomaterials in abundance in some or many compartments in the natural environment. Regardless of a nanomaterial's origin, their size and shape, and not just their chemical composition and atomic structure, are fundamental to their properties; this makes them distinct from materials existing at the macroscale in the Earth system (3).
Despite their overall ubiquity through time, nanomaterials are not considered in studies of biogeochemical processes throughout Earth's history, and collectively, they are only rarely considered at Earth scale within the complete Earth system. The reason for this may have been a lack of analytical tools, procedures, and practices to quantify the presence, abundance, sizes, shapes, compositions, and reactivities of nanomaterials, rather than scientific oversight. Only in the past 20 years, and particularly in the past decade, have their impacts on the Earth system, including ecology and human society, been rigorously studied. Indeed, we now know that nanomaterials play important, but not fully understood, roles in the dynamics of the Earth system and that nanomaterials are relevant on spatial scales from atomic to planetary, and on temporal scales from instantaneous to the span of geologic time. As a result, nanomaterials are intertwined with all space and time components of the Earth system (4). Important examples of this include the likely role of nanomineral surfaces in influencing the polymerization and selfassembly of the molecular building blocks of life and promoting the self-assembly of protocells in the origin of life and in the early evolution of bacterial cell walls (5-8); iron fertilization of the oceans by dissolution of natural iron oxyhydroxide nanominerals, which influences primary pro- ductivity and thus global temperature and the carbon cycle (9-11); and the global occurrence of nanoplastics in biota and other natural environments (12).

Exploring the role of nanomaterials in the Earth system requires a convergent approach that should typically combine physical, biological, and social sciences, as well as engineering and economic disciplines $(13,14)$. Nanomaterials are dynamic and often ephemeral phases that evolve chemically and physically over time through a complex combination of processes such as aggregation, biological assimilation, dissolution and evaporation, chemical alteration, shape change, and movement within the Earth system (15). Hence, the concept of nanomaterial transformation over time is essential to understanding their influence. This review is motivated by the need to learn how to recognize key and specific roles of all types of nanomaterials in the extraordinarily complex Earth system. The goal is that, ultimately, this understanding can be included in models of Earth processes and history, as well as in ethical considerations concerning their generation and impacts on current and future environmental and human health (16).

\section{Fundamental properties of nanomaterials}

Nanomaterials nucleate, grow, and dissolve via a set of elementary chemical processes that spontaneously redistribute charge and mass at the atomic scale. These processes include electron and proton transfer reactions that rearrange ions and complexes into nanophases. They can be understood by using thermodynamic, kinetic, and transition-state theory to describe intermediate states along reaction pathways on free-energy landscapes. Classical nucleation theory describes ion-by-ion assembly to

${ }^{1}$ Department of Geosciences, Virginia Tech, Blacksburg, VA 24061, USA. ${ }^{2}$ Subsurface Science and Technology Group, Energy and Environment Directorate, Pacific Northwest National Laboratory, Richland, WA 99352, USA. ${ }^{3}$ Department of Earth Sciences, Montana State University, Bozeman, MT 59717-3480, USA. ${ }^{4}$ Department of Chemistry, Colorado School of Mines, Golden, C0 80401, USA. ${ }^{5}$ Department of Biomedical Sciences and Pathobiology, Virginia-Maryland College of Veterinary Medicine, Blacksburg, VA 24061, USA. ${ }^{6}$ School of Marine Science and Policy, University of Delaware, Lewes, DE 19958, USA. ${ }^{7}$ Department of Civil and Environmental Engineering, Virginia Tech, Blacksburg, VA 24061, USA. ${ }^{8}$ Applied Functional Materials Group, Energy and Environment Directorate, Pacific Northwest National Laboratory, Richland, WA 99352, USA. ${ }^{9}$ Department of Materials Science and Engineering, Virginia Tech, Blacksburg, VA 24061, USA. ${ }^{10}$ Reactor Materials and Mechanical Design Group, Energy and Environment Directorate, Pacific Northwest National Laboratory, Richland, WA 99352. USA. ${ }^{11}$ Institute for Materials Chemistry and Engineering, Kyushu University, Kasuga, Fukuoka 8168580, Japan. ${ }^{12}$ Geochemistry Group, Physical and Computational Sciences Directorate, Pacific Northwest National Laboratory, Richland, WA 99352, USA. ${ }^{13}$ Department of Polymer Science, University of Akron, Akron, OH 44325-3909, USA. ${ }^{14}$ Department of Geology, University of Georgia, Athens, GA 30602, USA. ${ }^{15}$ School of Sustainable Engineering and Built Environment, Arizona State University, Tempe, AZ 85287, USA. ${ }^{16}$ Key Laboratory of Geographic Information Science of the Ministry of Education, School of Geographic Sciences, East China Normal University, Shanghai 200241, China.

*Corresponding author. Email: hochella@vt.edu 
form crystals, but nonclassical growth pathways are also important; these pathways involve formation of intermediate multinuclear ion clusters and small nanomaterials that can transition to relatively larger nanomaterials and bulk crystals by particle-based crystallization $(17,18)$.

The distinct properties of all natural and anthropogenic nanomaterials stem primarily from the comparatively high proportion of surface atoms relative to interior ones. At times, these properties are best described using quantum mechanics. Smaller particles have fewer atoms, which translates to fewer electron energy levels. Therefore, electron energy bands become dis- crete electron energy states, of energies that are sensitive to particle size, a condition known as quantum confinement. Nevertheless, however "nano" is defined or considered, size and shape are essential characteristics because they exert primary control over reactivity and transport physics. Size and shape also determine the types and distributions of reactive surface sites capable of chemical transformations and, at times, the toxicity of nanomaterials. Owing to the high proportion of surface versus bulk atoms, even the smallest variations in surface structures may control the fate and reactivity of nanomaterials in air, water, soil, or biota. Through their influence on surface charging behavior, size

\section{Fig. 1. Conceptual} free-energy landscape for the formation and interactions that define the typical state of nanomaterials in the environment. Shown are chemical formation mechanisms of nanomaterials, from complexes to clusters and beyond, within aqueous solutions. This creates nanomaterials (teal solid curve) that are more stable than the product of continuous growth (teal dashed curve), which results in larger bulk crystals (represented

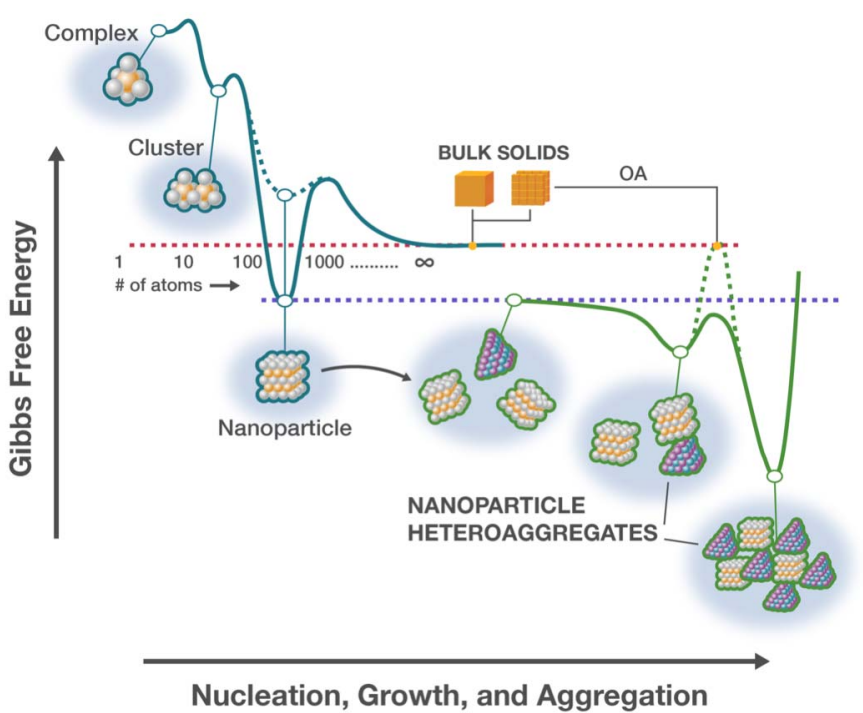

here as a precipitated single crystal or a crystal formed by oriented attachment of nanocrystals, OA) that have a free energy represented by the horizontal red dotted line. Moving across the graphic from left to right, as shown by the curved arrow, symbolizes the myriad interactions of stable nanomaterials in environmental media. Individual nanoparticles at an energy represented by the horizontal purple dotted line tend to form heteroaggregates at an even lower free-energy state.

Here, net attractive interactions with unlike particles and compounds (green curve) tend to outcompete processes that could lead to single-phase bulk crystals assembled by, for example, OA (green dashed curve), producing, instead, long-lived composites of complex composition and structure.

\section{Box 1. Definitions.}

Nanomaterials-Any organic, inorganic, or mixed (organometallic) material that presents distinct chemical, physical, and/or electrical properties owing to their ultrasmall size, typically in the nanoscale region (most often from $1 \mathrm{~nm}$ up to a few to several tens of nanometers).

Natural nanomaterials-A nanomaterial made by nature through (bio)geochemical or mechanical processes, without direct or indirect connection to a human activity or anthropogenic process.

Incidental nanomaterials-A nanomaterial unintentionally produced as a result of any form of direct or indirect human influence or anthropogenic process.

Engineered nanomaterials-A nanomaterial conceived, designed, and intentionally produced by humans.

Anthropogenic nanomaterials-Both incidental and engineered nanomaterials.

Note: The definition of "nanomaterial" is still an active area of scientific and policy debate (126), although small size, high surface area, and enhanced reactivity over bulk materials are universally accepted requirements. The definition given above is currently well within the mainstream of current thought and acceptance. and shape also control the tendency for aggregation, a critically important aspect that can blend or obscure the characteristics of individual particles as they adopt new characteristics in nanocomposites.

The interplay between growth, dissolution, evaporation, and aggregation are key aspects of nanomaterials in the environment (Fig. 1). Oriented aggregation can result in the formation of larger particles with complex shapes $(19,20)$. But because of the complexity of natural settings, most nanomaterials are found in heteroaggregated composites of different inorganic and organic materials. These aggregates can diverge markedly from spherical shapes and may even form highly branched or fractal structures, thereby fundamentally affecting transport properties and reactivities. Rates of particle dissolution, although known or experimentally measurable for many pure-phase nanomaterials in a welldispersed state $(11,21)$, are challenging to predict for complex nanomaterial aggregates that have substantial internal surface areas with limited accessibility (22). Furthermore, these physical associations change as the nanomaterials encounter and transition through different local environments. Only in relatively simple systems can the evolution of particle size, shape, and aggregation state, and thus the distribution of effective particle diameters, be predicted with reasonable accuracy (23).

\section{Earth's nanomaterial cycle}

The rock and water cycles of this planet, along with Earth's many chemical cycles, are of central importance to the Earth sciences. On the basis of our emerging understanding of nanomaterials in the environment, Earth also has a nanomaterial cycle (Fig. 2). Like other Earth cycles, the nanomaterial cycle helps to explain how Earth works as an overall system. The dynamics of and interactions between the three portions of the cycle-namely nanomaterial precursors; the natural, incidental, and engineered nanomaterials themselves; and Earth components such as continents, oceans, factories, and our atmosphere-are connected by chemical and physical processes of both natural and anthropogenic origin.

Nanomaterial precursors, illustrated in the upper right of Fig. 2, are commonly seen either as the starting point of a linear process of nanomaterial formation or as the beginning of a life cycle. Reality is much more complicated. As shown in Fig. 2, multiple pathways exist between precursors and the nanomaterials themselves. Reaction mechanisms that work alone or in concert in the formation of all nanomaterials are driven by redox processes that move electrons, hydrolysis processes that move protons, and dissolution and precipitation reactions that move cation and anion complexes. All of these paths are reversible (Fig. 1). When reactions do proceed to nanomaterial formation, further reaction progress can continue to a bulk material, or growth may stop in the nanoscale domain. In effect, nanomaterial formation and 


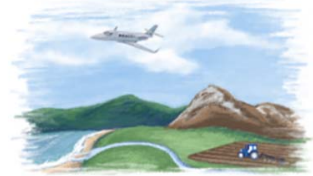

EARTH COMPONENTS

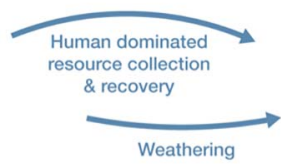

Weathering

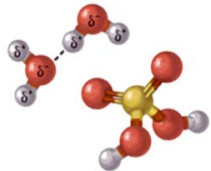

PRECURSORS

Electrons \& protons Small molecules/clusters Elements \& ions Polyatomic ions

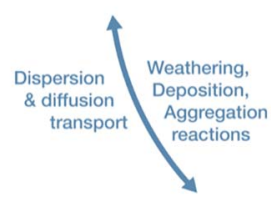

NANOMATERIAL $\therefore$ CYCLE
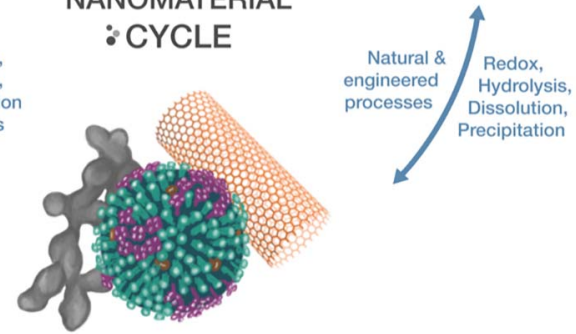

NANOMATERIAL EXAMPLES
INCIDENTAL

Magnéli phases Welding fumes Nanoplastics Soot
NATURAL

Metal oxides

Clay minerals Sulides
ENGINEERED

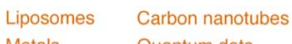

Fig. 2. Earth has not only water and rock cycles, and many chemical cycles, but also a nanomaterial cycle. Like the other cycles, the nanomaterial cycle is fundamental to how Earth works. Examples of the three nanomaterial types are shown at the bottom, along with their intimate and reversible connections to both their precursors, and the Earth components in which they participate. The cycle is complete when going from the Earth components back to the precursors via weathering and human resource recovery.

interaction with its surroundings play the role of a gatekeeper, dictating what materials can proceed to a bulk state, or not.

The precursors may originate from the natural process of weathering or from human mining of, for example, ore deposits or ocean water (Fig. 2). Weathering of rock and of living biological matter driven by a wide range of climates and organisms provides an enormous variety of fundamental chemical components. Engineered nanomaterials are different in that they can be made in large homogeneous batches. However, in engineered nanomaterial production, controlling the synthesis conditions comes at an environmental cost. Life-cycle analysis of engineered nanomaterials indicates that mining, ore beneficiation, and synthetic production are highly intensive activities and that they negatively affect atmospheric $\mathrm{CO}_{2}$ concentrations, soil nutrients, and human health (24).

The nanomaterial cycle is completed with the connection between the produced nanomaterials and Earth's natural and anthropogenic components (Fig. 2). Here, weathering or human-promoted breakdown of bulk materials can result in nanomaterials directly (a top down process), or nanomaterials can grow from precursors (a bottom up process). Once formed along either path, nanomaterials of all types and varieties are subject to dispersiveand diffusive-based movement or transport in the Earth system, including human-dominated components.

\section{Nanomaterials in and above the critical zone}

Earth's critical zone is the permeable near-surface layer from the treetops down through the soil profile, aquifers, and the bedrock below to where meteoric groundwater has penetrated (25). This zone includes all natural and humaninfluenced terrestrial environments. In the critical zone, the main producers of Earth's natural nanomaterials are weathering and mineral formation processes in soils. Clays formed through these processes are by far the most abundant naturally occurring inorganic nanomaterial, accounting for the great majority of the terrestrial $10^{7}$ - to $10^{8}-\mathrm{Tg}$ natural nanomaterial reservoir (4). Many other natural nanomaterials, such as metal oxides (most abundantly iron oxides), sulfides, carbonates, and phosphates, are also produced through weathering processes in the critical zone. These nanomaterials play major biogeochemical roles despite the fact that they are present in much lower quantities relative to clays $(3,4)$. The primary global movers of these natural nanomaterials are ground water, rivers, glaciers, wind, and ocean currents (Fig. 3). Rivers, and to a much lesser extent glaciers, bring approximately $10^{3}$ to $10^{4} \mathrm{Tg}$ of natural nanomaterials to continental edges and ocean margins each year (4). Airborne natural nanomaterials originate from mineral dust and volcanic emissions, estimated together at $342 \mathrm{Tg} /$ year; of this, $236 \mathrm{Tg} /$ year is estimated to settle back onto continents downwind from their source (4).
Microbial communities are intimately connected to natural nanomaterials. In soils, microbes create redox conditions to store and shuttle electrons through transient production of natural nanomaterials. An example is the heterotrophic formation and autotrophic usage of $\mathrm{FeS}_{2}$ in wetlands that influences denitrification rates (26). Magnetotactic bacteria produce iron oxides to directionally orient themselves in soils, and these natural nanomaterials may even affect magnetic soil properties (27).

Incidental nanomaterials are produced in the critical zone, on and below Earth's surface (especially in the most manipulated lands such as cities and industrial, agricultural, and mining areas) and in the troposphere (especially over industrial and highly populated areas). Since the Industrial Revolution, their abundance can be similar to or even exceed natural abundances in certain natural Earth compartments. Overall, however, much less is known about the formation, evolution, abundance, and movement of incidental nanomaterials, relative to natural nanomaterials.

The formation and nature of incidental nanomaterials in the subsurface in lands affected by mining and ore benefaction and smelting has been a field of growing research interest $(28,29)$. In some cases, incidental nanoparticles can preserve or record complex biogeochemical histories as they persist or evolve through changing environmental conditions. This understanding is important in assessing the longdistance transport of metal contaminants down hydrologic gradients in watersheds, and eventually to oceans. Nevertheless, the flux of subsurfaceproduced incidental nanomaterials to the oceans owing to anthropogenic land use is poorly constrained. For example, mining and agricultural practices are known to produce incidental nanomaterial-rich soils that can end up in flood plains and behind dams, all of which clearly influence nanomaterial transport to the oceans (30). This transport ultimately influences biogeochemical processes in the ocean margins and continental shelves.

Major amounts of incidental nanomaterials in the critical zone, released directly to the overlying atmosphere, result from the combustion of biomass and fossil fuels, as well as exhaust from industrial and agricultural operations. These materials range from complex aggregates of inorganic and organic compounds, some with crystalline structures (26), to carbonaceous "tar balls" and organic droplets $(31,32)$. Exhaust from gasoline and diesel engines contains graphitized carbon nanomaterials that are associated with metal and metal-oxide nanomaterials, polycyclic aromatic hydrocarbons (PAHs), nitrated PAHs, and heterocyclic aromatic compounds formed from vaporization and partial combustion of lubricants and fuel additives (29). Furthermore, nanomaterials form in the atmosphere as a result of the anthropogenic and natural emission of precursors, such as sulfuric acid and other compounds that form molecular clusters, which then grow into stable nanomaterials through 


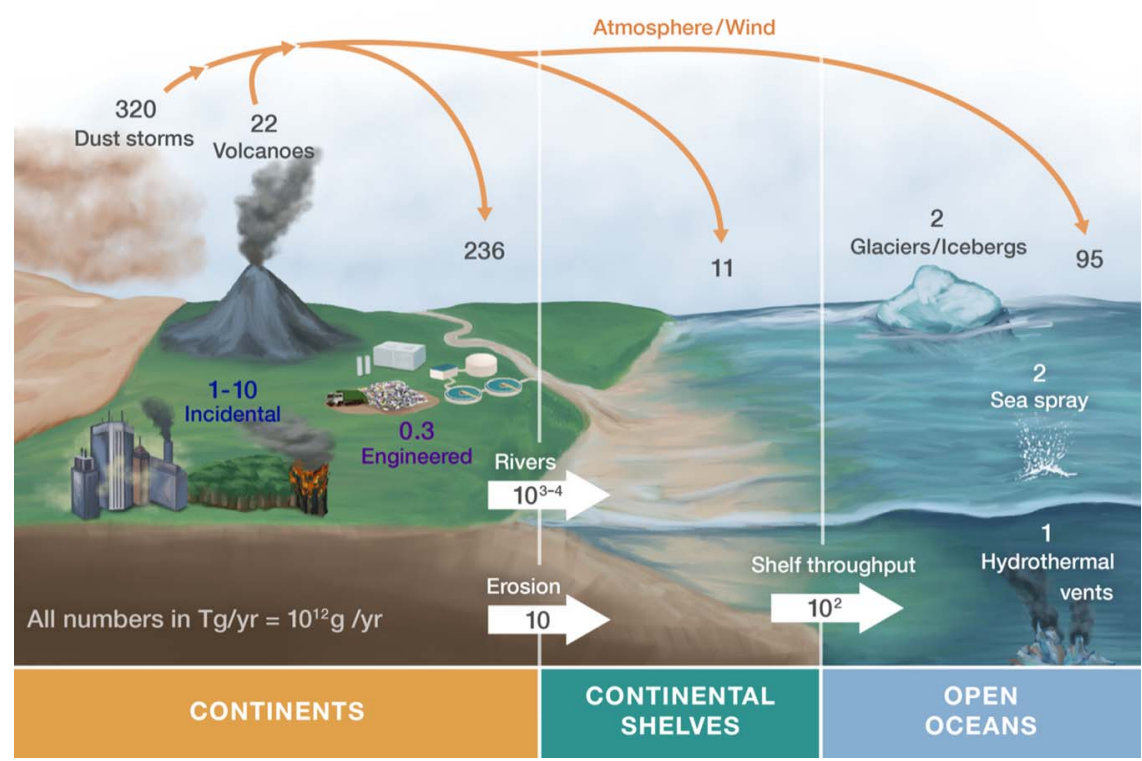

Fig. 3. An estimated global accounting for all natural, incidental, and engineered nanomaterials on or in Earth's surface and atmosphere. All numbers are fluxes (Tg/year), where $1 \mathrm{Tg}$ equals $10^{12} \mathrm{~g}$ or 1 million metric tons. Natural nanomaterial fluxes are illustrated using black and white numbers at their sources or destinations, and within the bold white arrows for natural nanomaterials movement from continents to continental shelves and from continental shelves to open oceans. The incidental nanomaterials annual flux to the atmosphere is given as a range between 1 and $10 \mathrm{Tg} /$ year, and the engineered nanomaterials annual flux to landfills, water, soil, and air is estimated at $0.3 \mathrm{Tg} /$ year [reference (43) for engineered nanomaterials only; all other estimates in the figure come from knowing $\mathrm{PM}_{2.5}$ or other particulate fraction and estimating what percentage of that is in the nanoscale range; see text for references].

condensation of organic vapors $(4,33)$. An estimated $74 \%$ of nanomaterials in the atmosphere at ground level arise through precursor nucleation (34). Atmospheric incidental nanomaterials grow into larger particles that act as cloud condensation nuclei and/or contribute to light absorption and scattering, which affect global warming processes.

Global release and formation of airborne incidental nanomaterials now rivals the production of certain natural nanomaterials. The production of airborne incidental nanomaterials can be roughly estimated from inventories of particulate matter emissions from industrial, forest fire, transportation, and agricultural sources (35), together with typical particle-size distributions of urban, rural, and marine incidental particles $(36,37)$. Using this method, we estimate that the annual atmospheric release is in the range of 1 to $10 \mathrm{Tg}$ (Fig. 3).

Finally, the critical zone houses all the industries (and their waste streams) that produce engineered nanomaterials. These factories utilize processes carried out in solution, gas, or solid phases, and under controlled reaction times and temperatures. These conditions dictate shape, size, and elemental composition of the resulting nanomaterials. In addition, biomimicking processes are being engineered to convert precursors into engineered nanomaterials. For example, metal ions form nanomaterials within bacteria,

nanomateric challenges $(40)$ or remediate heavy metals from mine drainage waters $(40,41)$.

Estimates of the total global production of engineered nanomaterials vary by at least an order of magnitude because manufacturers are reluctant to publicize these numbers (42). The most abundantly engineered nanomaterials, listed in order of approximate tonnage from highest to lowest, are $\mathrm{TiO}_{2}, \mathrm{SiO}_{2}, \mathrm{Fe}, \mathrm{ZnO}, \mathrm{Al}_{2} \mathrm{O}_{3}$, $\mathrm{CeO}_{2}, \mathrm{Cu}, \mathrm{Ag}$, carbon nanotubes and graphenes, and nanoclay composites (43). According to expert estimates, up to $0.3 \mathrm{Tg}$ of engineered nanomaterials enter landfills, soil, water, and air annually (43); still, this is dwarfed by the amounts of natural nanomaterials stored in the critical zone, as discussed above.

The pathways of these engineered nanomaterials during their lifetime can look quite different than natural and incidental nanomaterials. These engineered nanomaterials are used within an enormous range of commercial products. They can also be used as-is and dispersed directly into the environment as, for example, nano-based environmental remediation components or fertilizers. All eventually find their way to engineered structures (e.g., wastewater treatment plants), engineered reservoirs (e.g., landfills and holding ponds), and/or geologic reservoirs (e.g., soil, atmosphere, rivers, and oceans) (44-46).
From the descriptions above, natural, incidental, and engineered nanomaterials commingle in the critical zone. There are even many cases where all three types of nanomaterials are represented by the same or very closely related materials. One such case is nano-titanium oxide (nano-titania). Titania, in general, is exceptionally insoluble. Naturally occurring titania is therefore commonly found in soils, and it most commonly occurs as the minerals anatase and rutile (both with the formula $\mathrm{TiO}_{2}$ ) in sizes down to the nanometer scale (47). Oxygen-deficient nano-titania (specifically Magnéli phases, $\mathrm{Ti}_{x} \mathrm{O}_{2 x-1}$, where $4 \leq$ $x \leq 9$ ) particles are produced incidentally from anatase and rutile (which are naturally present in coal) during coal combustion in power plants and are released from the plants either in the coal ash or in the plant's gaseous exhaust. Unfortunately, these Magnéli nanophases have potentially serious ecotoxicological consequences (48). Engineered titania has distinct shapes such as tubes and rods; doping with sulfur, nitrogen, or carbon alters their light-absorbance properties. These properties are tuned to achieve desirable photocatalytic activity and produce hydroxyl radicals for air or water purification (49). Upon entering surface waters, this engineered titania continues to produce reactive oxygen species that influence biogeochemical processes (50). Weathering studies of engineered nanoscale titania have also revealed unexpectedly high aqueous titanium ion concentrations that are not predicted thermodynamically and that may influence its elemental cycling (51). These scenarios from just one type of nanomaterial in the critical zone of the Earth system show how remarkably complex and challenging these studies can be.

\section{Nanomaterials in and above the oceans}

More than $70 \%$ of Earth's surface is covered by oceans, and the overall Earth system is deeply rooted in their behavior. Yet surprisingly little is known about the types, characteristics, and distributions of nanomaterials in the oceans, far less than any other principal Earth component. Historically, nearly all oceanographers have used $0.20-\mu \mathrm{m}(200-\mathrm{nm})$ filters to separate "soluble" from particulate phases $(52,53)$. More recently, a few studies have used 20-nm filters, but even such small-pore filters let the smallest, nonagglomerated nanoparticles pass. Without further study, it is still not clear what chemistry in the filtrate is due to the truly soluble fraction and what is due to the smallest nanomaterials $(3,4,53)$. The material in the 20 - to 200 -nm fraction is referred to as colloidal, but this fraction, like others above this size range, contains nanomaterials that are found in (hetero)aggregates. For example, up to $80 \%$ of the iron in seawater (a vital and often limiting nutrient in the oceans) is found in the 20- to 200-nm-size fraction (52), whereas nearly all manganese is found in the $<20$-nm fraction (53), suggesting differences in the materials that contain these metals. The chemical or mineral nature of the $<200-\mathrm{nm}$ fraction is not normally investigated, but when 
considering iron in deep ocean nanomaterialcontaining heteroaggregates in the micron size range (54), synchrotron $x$-ray techniques indicate that iron (oxy)hydroxides are a crucial component. Various iron oxides are assumed to be in the $<200-\mathrm{nm}$ fraction, as previously shown using transmission electron microscopy (TEM) (55).

In addition to the in situ production of nanomaterials suggested above and discussed further below, it is also well known that natural nanomaterials are transported to the open oceans by (in order of amount, with the largest contributor first) atmospheric dust, riverine, glacial, and hydrothermal sources [Fig. 3; (4)]. More than $100 \mathrm{Tg}$ of natural nanomaterials is estimated to be transported to the world's open oceans each year from these sources, collectively (4). This is vital to the bioproductivity of the oceans $(3,56)$. A source not yet included, owing to lack of data, is from the submarine groundwater discharge from the continents to the oceans (not shown in Fig. 3). This discharge is equivalent to river-water flux to the oceans. Nanomaterial inputs due to this source are expected to be substantial.

The oceanographic community is beginning to sort out vital processes and impacts of at least some of the sources of nanomaterials to the oceans, particularly in the area of airborne aerosols just over the ocean surface, much of which will become part of the ocean system. Extensive studies of these samples (56), involving bulk chemical analyses of size-fractionated particles, suggest that larger particles (4 to $10 \mu \mathrm{m}$ in diameter) are mostly natural mineral dust particles and liquid droplets, whereas smaller ones $(<0.5 \mu \mathrm{m}$ in diameter) are typically anthropogenic, such as air pollutants (57). Metals are found in every size class, and although the compositions of nanoparticulate metal oxides are largely unknown, iron in aerosols collected in the western Pacific from the marine boundary layer was mostly in the form of colloidal (oxy)hydroxides (20 to $400 \mathrm{~nm}$ in diameter) rather than "dissolved" iron $(<20 \mathrm{~nm})(58)$. Another nanomaterial source for which new information is becoming available has to do with oceanic hydrothermal vents. Here, up to $10 \%$ of the iron in hydrothermal solutions emanating from vents into the oceans is contained in nanoparticulate pyrite $(59,60)$. In addition, cluster and nanoparticulate FeS has been identified, as well as mixed metal-sulfide nanomaterials. Metals from hydrothermal vents have also been detected in the deep oceans several kilometers from hydrothermal vent sources (61); it is suggested that the metals are contained in nano-iron (oxy)hydroxides, and perhaps also associated with organic matter as reduced materials become oxidized (61). Transporting these particles $4 \mathrm{~km}$ takes about 20 years and appears to be supported by exchange reactions between $<200$-nm and larger particulate fractions (62).

New ocean-based natural nanomaterial-related ocean processes are now being discovered. For example, $\mathrm{H}_{2} \mathrm{~S}$ gas is released from sediments off the coast of Namibia on a seasonal basis to surface waters, where it is oxidized by microbes to nanoparticulate $S_{8}$ that is distributed over thousands of square kilometers as observed by satellite (63). The water column becomes oxygen deficient, which negatively affects sea life.

The ocean can also act as a source for atmospheric nanomaterials through both physical and biochemical processes. The primary example of physical processes is the aerosols generated by bubble bursting in coastal breaking waves; $60 \%$ of these aerosols are smaller than $100 \mathrm{~nm}$ $(4,64)$. This results in an estimated direct emission of $2 \mathrm{Tg} /$ year of sea-spray natural nanomaterials to the atmosphere. Laboratory experiments suggest two size-distribution modes of sea-spray nanomaterials at $\sim 40$ and $\sim 100 \mathrm{~nm}$, and these may shift as a function of temperature, salinity, and surfactant concentration (61). Whereas larger sea-spray aerosols are dominated by the main components of seawater $(\mathrm{Cl}, \mathrm{Na}, \mathrm{Mg}$, and $\mathrm{S})$, natural sea-spray nanomaterials have organic content of up to $80 \%$ (65). Differences in the microorganisms that are present can affect both size and mixing state of sea-spray particles (66). Examples of biochemical processes as an ocean source for atmospheric nanomaterial generation is seen in the contributions of dimethylsulfide emitted by phytoplankton and iodine oxide emitted by kelp, in the formation of secondary natural nanomaterials (67).

By far, the major source of incidental nanomaterials over the oceans is due to engine exhausts from ocean-going ships. In terms of total particulate mass, exhaust emissions are nearly equivalent to those from all on-road vehicles (64). These emissions have a primary size distribution centered around $60 \mathrm{~nm}$, and sulfate is a major constituent of the nanomaterials (68). Any engineered nanomaterials found in and over the ocean would have to be transported there from the continents. In the future, they may be intentionally released for climate intervention purposes (3).

\section{Nanomaterials and biological systems}

Biological systems are continuously exposed to and affected by natural and anthropogenic nanomaterials, and insofar as the Earth system is so heavily influenced by biology, this is an important topic to cover in this review. Unfortunately, little is known about the full scale and scope of nanomaterial-biological interactions, especially for anthropogenic nanomaterials in the complex biosystems of both natural and engineered environments. A portion of these issues, relating specifically to human exposure, were framed very well more than a decade ago (69). This paper was one of the first to lay out the vast landscape of intricate pathways by which nanomaterials can affect the human biological system. There have been many excellent studies since, a few of which are cited here, dealing with incidental and engineered nanomaterials. There are also some multinational projects at the cutting edge of this field, which are continually updated. A good example of this is the Nanomaterial Fate and Speciation in the Environment, or NanoFASE (70), funded by the European Union.
The challenges encountered in biology-Earth system studies are illustrated in the literature concerning biointeractions of degrading plastics in natural environments. Microplastics are widely distributed across the Earth system (71) via a variety of pathways, including the breakdown of synthetic textiles, tire particles, and the reentrainment of dust that contains plastic residues (72). Many environmentally mediated processes can further degrade microplastics into nanoscale plastics (nanoplastics, an incidental nanomaterial). A recent study estimated that between 1.15 million and 2.41 million metric tons are transported to the world's oceans by rivers annually (73). However, because quantification of nanoplastic contaminants in environmental media is analytically challenging, the magnitude and detailed pathways of all fluxes of these nanomaterials through the environment are very difficult to determine. Laboratory studies have helped by showing that nanoplastics are subject to photochemical, mechanical, and atmospheric processing, with the ultimate environmental fate dependent on the underlying polymer identity (74). For example, glassy polymers (e.g., polyvinylchloride) tend to be stronger and less susceptible to photodegradation than rubbery polymers (e.g., polypropylene) (12). The long life and high ingestion rates of these nanoplastics can have considerable detrimental impacts on biological systems, including deleterious effects on larval development and efficient passaging through aquatic food chains (75).

Atmospheric incidental and engineered nanomaterials are also an important environmental health concern. About 3.3 million premature deaths occur annually owing to cardiovascular and respiratory injury from air pollution from particulate matter with a diameter less than $2.5 \mu \mathrm{m}\left(\mathrm{PM}_{2.5}\right)(76)$. Industrial coal burning is one of the most sizeable contributors to global air pollution. Nanomaterials are a predominant component (by number) of $\mathrm{PM}_{2.5}$ (26). These incidental nanomaterials readily penetrate the alveolar membranes of the lungs and translocate into the bloodstream, often concentrating distally in vital organs (77). For example, gold nanoparticles inhaled by humans were found translocated from the lung into the circulatory system and accumulated at sites of vascular inflammation (78). In this study (and several others), nanomaterial translocation was sizedependent; smaller nanoparticles showed greater translocation and accumulation. Another recent and particularly revealing study (79) found magnetite $\left(\mathrm{Fe}_{3} \mathrm{O}_{4}\right)$ incidental nanoparticles, clearly produced by fuel combustion as evidenced by its crystal morphology (80), in human brain tissue. These high-temperature-formed nanomaterials can enter the brain directly through the olfactory bulb (78) and are thought to have potentially negative consequences on brain health. Other toxic atmospheric incidental nanomaterials are still being discovered. For example, in 2017, Yang et al. (48) found incidental nano-Magnéli phases (oxygendeficient titanium oxides) in the atmospheric emissions of coal-burning power plants. These 
phases are spread locally, regionally, and even globally and are toxic to zebra fish embryos, suggesting biotoxicity in the environment (48).

Although many types of nanomaterials have detrimental impacts on biological systems, it is critical to note the promise of engineered nanomaterials in a broad range of industrial, agricultural, and medical applications benefiting humans (Fig. 4), all of which either directly or indirectly affect the Earth system. For example, nanomaterials in solar cells, batteries, and industrial materials are revolutionizing consumer electronics and aerospace products (81). In agriculture, nanomaterials are being used to improve plant yields and replace potentially harmful pesticides to improve food production for the world's growing population (82). Nano-enabled water-treatment devices hold promise to transition away from continuous chemical addition and to strategies that use catalytic and other distinct nanoscale properties to disinfect pathogens and purify water (83). Nanoadditives, including $\mathrm{TiO}_{2}$ and $\mathrm{ZnO}$ rods, are replacing chemical additives in personal care and hygiene products that may ultimately be less harmful to reef ecosystems (50).

\section{Implications in natural and engineered environments}

Although knowledge of the influence of nanomaterial fluxes on the Earth system is far from complete, it is clear that Earth system components are affected by their presence. This is typically due to their reactivity and their potential to alter system characteristics, such as contaminant and nutrient mobility (84). These processes are inherently local in nature, but they can have temporally and spatially dynamic regional and global environmental impacts. Take, for example, climate effects on terrestrial components and processes, and more specifically, the impacts of changing climate on soils and weathering $(85,86)$. The concentration of atmospheric $\mathrm{CO}_{2}$ has changed substantially over the past decades, increasing from around 320 to 410 parts per million (in 2018), which is resulting in higher temperatures and climate modification. The resulting changes in daily, seasonal, and interannual temperatures; wet and dry cycles; localized intensive rainfall; and extended periods of drought, permafrost, heat waves, and wildfires (87) are causing, or are expected to cause, substantial changes in soil properties, which will affect agriculture and food production and forests and other ecosystems, as well as surface and ground water quality (85). Climate change will induce accelerated weathering of rocks and sediments and the subsequent formation and/or release of natural nanomaterials. These nanomaterials will dynamically affect biotic and abiotic processes and reactions that both produce and transform other organic and inorganic nanomaterials initially within critical zone components, but ultimately in riverine and oceanic environments.

An example is provided by climate changeinduced glacier retreat, which is a worldwide phenomenon that has local, regional, and global impacts on natural nanomaterial loading. Sampling from glacial and nonglacial rivers that drain similar geologic terranes in eastern Iceland $(86,88)$ indicates that increasing temperatures over time have resulted in greatly enhanced particulate release in glacial rivers compared with nonglacial rivers. This is very important because biologically critical and limiting trace elements, primarily Fe and $\mathrm{P}$, are contained in these particulates traveling to the ocean. These studies did not measure particulate size, and they used the operational practice of separating soluble from insoluble fractions using $0.2-\mu \mathrm{m}(200-\mathrm{nm})$ filtration. Some nanomaterials do pass through these filters, but most are contained in aggregates and will be retained by $0.2-\mu \mathrm{m}$ filters $(89,90)$. Similarly, enhanced melting of sea ice and icebergs will release entrained dust and glacial flour; melting of icebergs that drift on the ocean surface permits release of these same limiting nutrients, mostly in bioavailable nanomaterials, resulting in increased phytoplankton productivity $(91,92)$.

As discussed earlier in this article, incidental nanomaterials will likely form in different environmental settings as a result of a variety of anthropogenic activities. One such example is the injection and storage of atmospheric $\mathrm{CO}_{2}$ in deep subsurface reservoirs. Studies suggest that if the $\mathrm{CO}_{2}$ escapes from these reservoirs and makes its way to aquifers, the acidification will induce more chemical weathering of rocks and

\section{NANOPARTICLE IMPACT}
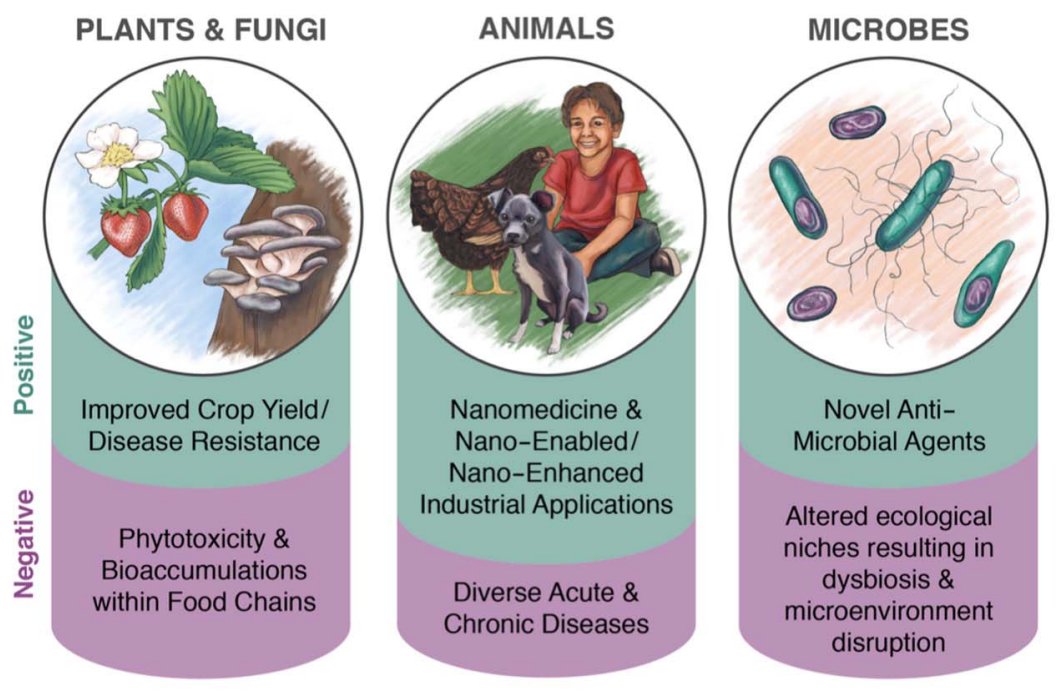

Fig. 4. Anthropogenic and natural nanomaterials enter biological systems across the tree of life through multiple routes, where they have broad positive and/or negative impacts. These impacts are driven by multiple factors, including the dose, duration, number of exposures, and the characteristics of the nanomaterial. Although it is clear that many nanomaterials have either beneficial effects or are innocuous, detrimental properties have also been observed. If the latter, it is likely that the offending nanomaterial is anthropogenic, that is, incidental or engineered. Such situations typically require extensive study to define their specific nanomaterial toxicity. This can lead to useful risk assessments and development of preventive measures to ensure biological safety. 
(95). Waste streams entering wastewater treatment plants contain natural nanomaterials and residual engineered nanomaterials from consumer products and industrial processes. They also contain incidental nanomaterial precursors such as reduced metals $(96,97)$. All of these nanomaterials interact with the biogenic components of treatment plants (98). These nanomaterials may affect the interdependent microbial communities harbored within the treatment plant that carry out vital functions for pollutant (pathogen, pharmaceutical, and so on) transformation or removal. The advent of metagenomic methods has enabled high-resolution taxonomic and functional characterization of complex ecosystems (99), and metagenomic profiling has recently illustrated that both nanomaterial shape and surface coating affect wastewater microbial communities (100). In this study, the microbial community was shown to shift phylogenetically in response to chemically and colloidally stable gold nanospheres and nanorods that were surface functionalized with either cetyltrimethylammonium bromide or polyacrylic acid, showing also that nanomaterial shape is particularly important (100). Similar ecosystemlevel impacts of nanomaterial fluxes have been observed across a variety of ecological systems (101).

\section{New opportunities for research}

Fundamental and applied nanomaterial-Earth system sciences are beginning to gain traction on multiple fronts. Grand challenges now focus on understanding as many nanomaterial-mediated Earth system processes as possible. From this, one must tie these insights together to start to gain a more holistic sense of all classes of nanomaterialEarth system scenarios. For example, accelerating urbanization will affect nanomaterial-mediated processes, with localized consequences to environmental and human health in the built environment (102). Evolution of energy production systems will drive changes in the sources and distribution of nanomaterials, with global-scale consequences. Continued developments in analytical techniques, computational simulations, and conceptual models are key to pursuing these research opportunities. Excellent examples of very recent research that not only advances our understanding of nanomaterials in complex natural environments but also highlights the distinct behavior of nanomaterials include a functional assay strategy for nanomaterial risk prediction (103) and evidence that nanomaterial transport and uptake vary as a function of size in long-term wetland mesocosm experiments (104).

Emerging nanoscale dynamic measurement techniques will now allow changes in the abundance and characteristics of dispersed nanomaterials in various environmental compartments to be captured (105). The advent of single-particle inductively coupled plasma mass spectrometry (spICP-MS) over the past decade allows rapid particle-by-particle analysis (106), with further advancements coming from multielement nanomaterial analysis by spICP time-of-flight MS (107). However, standardized protocols for or biological samples containing nanomaterials are yet to be developed. A particularly important open question is if the original in situ aggregation state can be reliably observed in laboratory analyses of collected samples.

Advances in electron microscopy are enabling new opportunities in understanding nanomaterial chemistry and physics in complex environments. In situ liquid-flow cell TEM eliminates the need for exposing samples to high-vacuum of nanomaterial processes, such as nucleation and oriented attachment (108). Furthermore, it nanometer electron tomographic imaging by fast continuous image acquisition, thus enabling assessment of intrinsic nanomaterial properties by applying external stimuli within the electron microscope. Cryo-tomography TEM, used in molecular biology, could be introduced to nanogeoscience for examining organic-nanomaterial aggregates. Soft x-ray emission spectroscopy systems mounted within scanning electron microscopes (SEMs) and electron microprobes (EPMA) $(109,110)$ have also been developed. This technique provides better elemental sensitivity for light elements as well as the chemical state determination of many elements. This development seamlessly bridges the gap between atomic and nanoscale (TEM) and micro- and mesoscale (SEM and EPMA) measurements. proper sampling, storage, and processing of field conditions and has enabled dynamic observation is possible to add temporal resolution to sub-

Use of advanced computing now allows exploration of nanomaterial properties, such as relationships between size, shape, and total free energy, at the whole-particle scale in solvated environments. Defining the size region at which nanoscale properties are apparent is key. With combined theory, simulation, and measurement, it is now possible to explore pathways and mechanisms from atoms to clusters to nanomaterials. Similarly, developing the ability to accurately predict aggregation behavior as it evolves in time is a critical emergent research frontier. Aggregation is sensitive to interparticle van der Waals forces, hydration forces, and surface electrostatic forces that are subject to specific environmental variables (such as hydration state, $\mathrm{pH}$, and electrolyte type and concentration), as well as hydrodynamic forces of flow. Classical surface charge-force models in a liquid medium [such as Derjaguin-Landau-Verwey-Overbeek (DLVO)] need to be extended to encompass nonspherical particle shapes and the molecular-level details that give rise to steric, hydration, and ion correlation forces between particles (111, 112). Direct measurements of interparticle forces in controlled environments with very high precision are now possible $(113,114)$. Present-day molecular simulations can encompass aspects of directionspecific nanomaterial interactions in aqueous solutions, such as predicting potentials of mean force for direction-specific interactions $(113,115)$. However, much remains unknown about the fundamental basis for oriented versus nonoriented aggregation and homo- versus heteroaggregation.

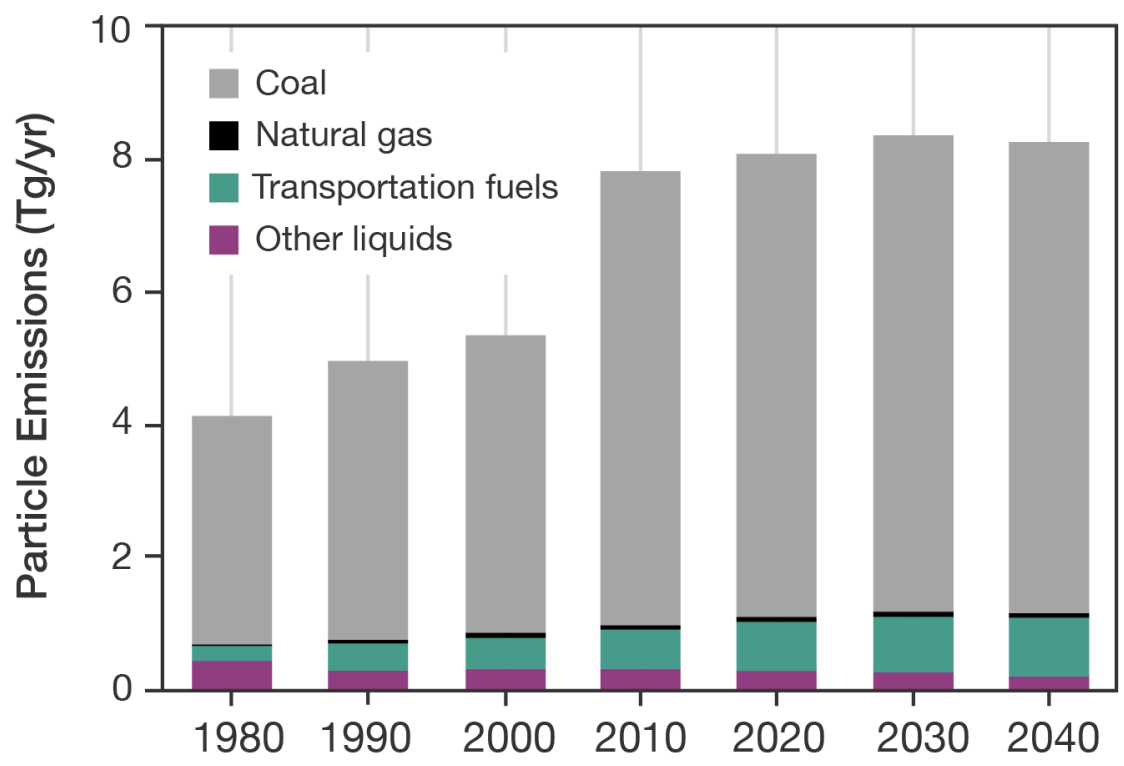

Fig. 5. Past and projected future atmospheric emissions of particulates $\left(\mathrm{PM}_{2.5}\right)$ from combustion of fossil fuels. These estimates were calculated by using an aggregate energy-specific particulate emission factor computed for each fuel type and then multiplying by the historic and projected future global consumption of each of these fuels. Coal emission factors were derived from contributions from power generation, industrial, and domestic uses. Emission factors for natural gas were attributed to primary uses in power generation and industrial processes. Oil emission factors were divided into emissions for individual transportation fuels (gasoline and diesel, heavy fuel oil, and Jet-A) and other liquids. See text for references. 
These gaps highlight the need for a greatly improved theoretical and conceptual framework for understanding aggregation forces, and for statistical sampling and analytical methods to address the energetics, kinetics, pathways, and fluxes of these transformations.

In particular, evolution of the global energy system will continue to drive changes in global sources and distribution of nanomaterials, especially those directly produced by combustion. Continued growth in use of fossil fuels is very likely over the balance of this century owing to its ease of use, relatively low costs (purely economically, excluding environmental impacts), and dominant role in electric power generation, transportation, and industrial processes. As a result, global incidental nanomaterials discharged to the major pathways shown in Fig. 3 will continue to increase through the middle of this century (Fig. 5) (116-124). Also, the amount of nanomaterials in these emissions will be considerable. Nevertheless, emissions from coal use dominate the sources, even though total energy contribution from coal will be at parity or less than other fossil fuels after 2025. Nanomaterial emissions from the transportation sector, however, are growing fastest and are expected to quadruple between 1980 and 2040 .

New technologies being developed to improve efficiency and reduce $\mathrm{CO}_{2}$ emissions at less cost (such as oxy-fueled coal combustion) (125) and increasing use of bio-based fuels for transportation are promising but also raise important scientific questions about unintended and presently unexplored impacts on the quantity, chemical composition, and toxicity of nanomaterials generated by deployment of these technologies. However, scientists right now are equipped with the necessary tools, methods, and, most importantly, awareness of the interconnection between natural, incidental, and engineered nanomaterial generation and transport, and their impacts on global human and environmental health. This should affect future energy choices worldwide.

The new scientific insights and technical developments afforded by the nanotechnology revolution have allowed scientists and engineers to begin to fill in a previously missing piece in our understanding of the Earth system. Like the other technical revolutions originating in the last century (molecular biology and nuclear, neurocognitive, and information sciences and technologies), nanoscience and technology, including natural, incidental, and engineered nanomaterials, are fundamental to how we understand Earth.

\section{REFERENCES AND NOTES}

1. W. Stöber, A. Fink, E. Bohn, Controlled growth of monodisperse silica spheres in the micron size range. J. Colloid Interface Sci. 26, 62-69 (1968). doi: 10.1016/00219797(68)90272-5

2. J. R. Bursten et al., Nano on reflection. Nat. Nanotechnol. 11 828-834 (2016). doi: 10.1038/nnano.2016.232: pmid: 27703248

3. M. F. Hochella Jr. et al., Nanominerals, mineral nanoparticles, and Earth systems. Science 319, 1631-1635 (2008). doi: 10.1126/science.1141134; pmid: 18356515

4. M. Hochella, D. Aruguete, B. Kim, A. Elwood Madden, "Naturally occurring inorganic nanoparticles: General assessment and a global budget for one of Earth's last unexplored major geochemical components," in Nature's Nanostructures, A. S. Barnard, H. Guo, Eds. (Pan Stanford Publishing Pte. Ltd., Singapore, 2012), pp. 1-42.

5. J. P. Ferris, G. Ertem, Oligomerization of ribonucleotides on montmorillonite: Reaction of the 5'-phosphorimidazolide of adenosine. Science 257, 1387-1389 (1992). doi: 10.1126/ science.1529338; pmid: 1529338

6. T. A. Oleson, N. Sahai, J. A. Pedersen, Electrostatic effects on deposition of multiple phospholipid bilayers at oxide surfaces. J. Colloid Interface Sci. 352, 327-336 (2010) doi: 10.1016/j.jcis.2010.08.057; pmid: 20869065

7. J. Xu, J. M. Campbell, N. Zhang, W. J. Hickey, N. Sahai, Did mineral surface chemistry and toxicity contribute to evolution of microbial extracellular polymeric substances? Astrobiology 12, 785-798 (2012). doi: 10.1089/ast.2011.0776; pmid: 22934560

8. N. Sahai et al., Mineral surface chemistry and nanoparticleaggregation control membrane self-assembly. Sci. Rep. 7

43418 (2017). doi: 10.1038/srep43418; pmid: 28266537

9. K. H. Coale et al., A massive phytoplankton bloom induced by an ecosystem-scale iron fertilization experiment in the equatorial Pacific Ocean. Nature 383, 495-501 (1996) doi: 10.1038/383495a0; pmid: 18680864

10. S. Blain et al., Effect of natural iron fertilization on carbon sequestration in the Southern Ocean. Nature 446, 1070-1074 (2007). doi: 10.1038/nature05700; pmid: 17460670

11. D. M. Cwiertny, G. J. Hunter, J. M. Pettibone, M. M. Scherer, V. H. Grassian, Surface chemistry and dissolution of $\alpha-\mathrm{FeOOH}$ nanorods and microrods: Environmental implications of size-dependent interactions with oxalate. J. Phys. Chem. C 113, 2175-2186 (2009) doi: $10.1021 /$ jp807336t

12. O. S. Alimi, J. Farner Budarz, L. M. Hernandez, N. Tufenkji, Microplastics and nanoplastics in aquatic environments: Aggregation, deposition, and enhanced contaminant transport. Environ. Sci. Technol. 52, 1704-1724 (2018) doi: 10.1021/acs.est.7b05559; pmid: 29265806

13. National Research Council, Convergence: Facilitating Transdisciplinary Integration of Life Sciences, Physical Sciences, Engineering, and Beyond (The National Academies Press, Washington, DC, 2014), pp. 152.

14. M. K. McNutt, Convergence in the geosciences. GeoHealth 1 , 2-3 (2017). doi: 10.1002/2017GH000068

15. G. V. Lowry, K. B. Gregory, S. C. Apte, J. R. Lead Transformations of nanomaterials in the environment. Environ. Sci. Technol. 46, 6893-6899 (2012). doi: 10.1021/ es300839e; pmid: 22582927

16. A. Nordmann, A. Rip, Mind the gap revisited. Nat. Nanotechnol. 4, 273-274 (2009). doi: 10.1038/nnano.2009.26 pmid: 19421202

17. J. J. De Yoreo et al., Crystallization by particle attachment in synthetic, biogenic, and geologic environments. Science 349, eaaa6760 (2015). doi: 10.1126/science.aaa6760; pmid: 26228157

18. A. E. S. Van Driessche, T. M. Stawski, L. G. Benning M. Kellermeier, in New Perspectives on Mineral Nucleation and Growth: From Solution Precursors to Solid Materials, A. E. S. Van Driessche, M. Kellermeier, L. G. Benning, D. Gebauer, Eds. (Springer, 2017), pp. 227-256.

19. R. L. Penn, J. F. Banfield, Imperfect oriented attachment: Dislocation generation in defect-free nanocrystals. Science 281, 969-971 (1998). doi: 10.1126/science.281.5379.969; pmid: 9703506

20. R. L. Penn, J. F. Banfield, Oriented attachment and growth, twinning, polytypism, and formation of metastable phases: Insights from nanocrystalline $\mathrm{TiO}_{2}$. Am. Mineral. 83, 1077-1082 (1998). doi: 10.2138/am-1998-9-1016

21. J. J. Schoepf et al., Detection and dissolution of needle-like hydroxyapatite nanomaterials in infant formula. Nanolmpact 5, 22-28 (2017). doi: 10.1016/j.impact.2016.12.007

22. J. Liu, D. M. Aruguete, J. R. Jinschek, J. Donald Rimstidt, M. F. Hochella Jr., The non-oxidative dissolution of galena nanocrystals: Insights into mineral dissolution rates as a function of grain size, shape, and aggregation state. Geochim Cosmochim. Acta 72, 5984-5996 (2008). doi: 10.1016/ j.gca.2008.10.010

23. K. M. Mullaugh, G. W. Luther, Growth kinetics and long-term stability of CdS nanoparticles in aqueous solution under ambient conditions. J. Nanopart. Res. 13, 393-404 (2011). doi: 10.1007/s11051-010-0045-9

24. M. Miseljic, S. I. Olsen, Life-cycle assessment of engineered nanomaterials: A literature review of assessment status.
J. Nanopart. Res. 16, 2427 (2014). doi: 10.1007/ s11051-014-2427-x

25. P. A. Schroeder, Clays in the Critical Zone (Cambridge Univ. Press, 2018), pp. 254

26. T. Hosono, K. Alvarez, I. T. Lin, J. Shimada, Nitrogen, carbon, and sulfur isotopic change during heterotrophic (Pseudomonas aureofaciens) and autotrophic (Thiobacillus denitrificans) denitrification reactions. J. Contam. Hydrol. 183, 72-81 (2015). doi: 10.1016/j.jconhyd.2015.10.009; pmid: 26529303

27. J. A. Dearing et al., Magnetic susceptibility of soil: An evaluation of conflicting theories using a national data set. Geophys. J. Int. 127, 728-734 (1996). doi: 10.1111/ j.1365-246X.1996.tb04051.x

28. M. F. Hochella Jr. et al., Direct observation of heavy metalmineral association from the Clark Fork River Superfund Complex: Implications for metal transport and bioavailability. Geochim. Cosmochim. Acta 69, 1651-1663 (2005). doi: 10.1016/j.gca.2004.07.038

29. M. Schindler, M. F. Hochella Jr., Soil memory in mineral surface coatings: Environmental processes recorded at the nanoscale. Geology 43, 415-418 (2015). doi: 10.1130/G36577.1

30. C. van der Zee, D. R. Roberts, D. G. Rancourt, C. P. Slomp, Nanogoethite is the dominant reactive oxyhydroxide phase in lake and marine sediments. Geology 31, 993-996 (2003). doi: 10.1130/G19924.1

31. R. K. Chakrabarty et al., Brown carbon in tar balls from smoldering biomass combustion. Atmos. Chem. Phys. 10, 6363-6370 (2010). doi: 10.5194/acp-10-6363-2010

32. L. Tumolva et al., Morphological and elemental classification of freshly emitted soot particles and atmospheric ultrafine particles using the TEM/EDS. Aerosol Sci. Technol. 44, 202-215 (2010). doi: 10.1080/02786820903518907

33. M. Kulmala et al., Chemistry of atmospheric nucleation: On the recent advances on precursor characterization and atmospheric cluster composition in connection with atmospheric new particle formation. Annu. Rev. Phys. Chem. 65 21-37 (2014). doi: 10.1146/annurev-physchem-040412-110014; pmid: 24245904

34. J. Merikanto, D. V. Spracklen, G. W. Mann, S. J. Pickering, K. S. Carslaw, Impact of nucleation on global CCN. Atmos. Chem. Phys. 9, 8601-8616 (2009). doi: 10.5194/ acp-9-8601-2009

35. Y. Huang et al., Quantification of global primary emissions of $\mathrm{PM}_{2.5}, \mathrm{PM}_{10}$, and TSP from combustion and industrial process sources. Environ. Sci. Technol. 48, 13834-13843 (2014). doi: 10.1021/es503696k; pmid: 25347079

36. X. Xue, R. L. Penn, E. R. Leite, F. Huang, Z. Lin, Crystal growth by oriented attachment: Kinetic models and control factors. CrystEngComm 16, 1419-1429 (2014). doi: 10.1039/c3ce42129e

37. J. H. Seinfeld, S. N. Pandis, Atmospheric Chemistry and Physics: From Air Pollution to Climate Change (Wiley, 1998).

38. J. Huang et al., Bio-inspired synthesis of metal nanomaterials and applications. Chem. Soc. Rev. 44, 6330-6374 (2015). doi: 10.1039/C5CS00133A; pmid: 26083903

39. H. Korbekandi, S. Iravani, S. Abbasi, Production of nanoparticles using organisms. Crit. Rev. Biotechnol. 29 279-306 (2009). doi: 10.3109/07388550903062462; pmid: 19929319

40. V. S. Coker et al., Harnessing the extracellular bacterial production of nanoscale cobalt ferrite with exploitable magnetic properties. ACS Nano 3, 1922-1928 (2009). doi: 10.1021/nn900293d; pmid: 19507866

41. S. De Corte, T. Hennebel, B. De Gusseme, W. Verstraete, N. Boon, Bio-palladium: From metal recovery to catalytic applications. Microb. Biotechnol. 5, 5-17 (2012). doi: 10.1111/ j.1751-7915.2011.00265.x; pmid: 21554561

42. B. Giese et al., Risks, release and concentrations of engineered nanomaterial in the environment. Sci. Rep. 8, 1565 (2018) doi: 10.1038/s41598-018-19275-4; pmid: 29371617

43. A. A. Keller, A. Lazareva, Predicted releases of engineered nanomaterials: From global to regional to local. Environ. Sci. Technol. Lett. 1, 65-70 (2013). doi: 10.1021/ez400106t

44. W. C. Walker, C. J. Bosso, M. Eckelman, J. A. Isaacs, L. Pourzahedi, Integrating life cycle assessment into managing potential EHS risks of engineered nanomaterials: Reviewing progress to date. J. Nanopart. Res. 17, 344 (2015). doi: 10.1007/s11051-015-3151-x

45. M. M. Falinski et al., A framework for sustainable nanomaterial selection and design based on performance, 
hazard, and economic considerations. Nat. Nanotechnol. 13, 708-714 (2018). doi: 10.1038/s41565-018-0120-4; pmid: 29713076

46. R. S. Lankone et al., Methodology for quantifying engineered nanomaterial release from diverse product matrices under outdoor weathering conditions and implications for life cycle assessment. Environ. Sci. Nano 4, 1784-1797 (2017). doi: 10.1039/C7EN00410A

47. P. A. Schroeder, J. Shiflet, Ti-bearing phases in the Huber Formation, an east Georgia kaolin deposit. Clays Clay Miner. 48, 151-158 (2000). doi: 10.1346/CCMN.2000.048020

48. Y. Yang et al., Discovery and ramifications of incidental Magnéli phase generation and release from industrial coal-burning. Nat. Commun. 8, 194 (2017). doi: 10.1038/ s41467-017-00276-2; pmid: 28790379

49. A. Fujishima, X. T. Zhang, D. A. Tryk, $\mathrm{TiO}_{2}$ photocatalysis and related surface phenomena. Surf. Sci. Rep. 63, 515-582 (2008). doi: 10.1016/j.surfrep.2008.10.001

50. D. Hanigan et al.. Trade-offs in ecosystem impacts from nanomaterial versus organic chemical ultraviolet filters in sunscreens. Water Res. 139, 281-290 (2018). doi: 10.1016/ j.watres.2018.03.062; pmid: 29656193

51. R. D. Holbrook et al., Titanium distribution in swimming pool water is dominated by dissolved species. Environ. Pollut. 181, 68-74 (2013). doi: 10.1016/j.envpol.2013.05.044; pmid: 23820189

52. J. N. Fitzsimmons, E. A. Boyle, W. J. Jenkins, Distal transport of dissolved hydrothermal iron in the deep South Pacific Ocean. Proc. Natl. Acad. Sci. U.S.A. 111, 16654-16661 (2014) doi: 10.1073/pnas.1418778111; pmid: 25349389

53. V. E. Oldham, A. Mucci, B. M. Tebo, G. W. Luther III, Soluble $\mathrm{Mn}(\mathrm{III})-\mathrm{L}$ complexes are abundant in oxygenated waters and stabilized by humic ligands. Geochim. Cosmochim. Acta 199, 238-246 (2017). doi: 10.1016/j.gca.2016.11.043

54. B. M. Toner, C. R. German, G. J. Dick, J. A. Breier, Deciphering the complex chemistry of deep-ocean particles using complementary synchrotron $x$-ray microscope and microprobe instruments. Acc. Chem. Res. 49, 128-137 (2016). doi: 10.1021/acs.accounts.5b00282; pmid: 26636984

55. M. L. Wells, E. D. Goldberg, The distribution of colloids in the North Atlantic and Southern Oceans. Limnol. Oceanogr. 39, 286-302 (1994). doi: 10.4319/lo.1994.39.2.0286

56. P. L. Morton et al., Methods for the sampling and analysis of marine aerosols: Results from the 2008 GEOTRACES aerosol intercalibration experiment. Limnol. Oceanogr. Methods 11 62-78 (2013). doi: 10.4319/lom.2013.11.62

57. C. Mead, P. Herckes, B. J. Majestic, A. D. Anbar, Source apportionment of aerosol iron in the marine environment using iron isotope analysis. Geophys. Res. Lett. 40 5722-5727 (2013). doi: 10.1002/2013GL057713

58. A. M. Aguilar-Islas, J. Wu, R. Rember, A. M. Johansen, L. M. Shank, Dissolution of aerosol-derived iron in seawater: Leach solution chemistry, aerosol type, and colloidal iron fraction. Mar. Chem. 120, 25-33 (2010). doi: 10.1016/ j.marchem.2009.01.011

59. M. Yücel, A. Gartman, C. S. Chan, G. W. Luther, Hydrothermal vents as a kinetically stable source of iron-sulphide-bearing nanoparticles to the ocean. Nat. Geosci. 4, 367-371 (2011). doi: 10.1038/ngeo1148

60. A. Gartman, A. J. Findlay, G. W. Luther III, Nanoparticulate pyrite and other nanoparticles are a widespread component of hydrothermal vent black smoker emissions. Chem. Geol. 366, 32-41 (2014). doi: 10.1016/j.chemgeo.2013.12.013

61. J. A. Resing et al., Basin-scale transport of hydrothermal dissolved metals across the South Pacific Ocean. Nature 523 200-203 (2015). doi: 10.1038/nature14577; pmid: 26156374

62. J. N. Fitzsimmons et al., Iron persistence in a distal hydrothermal plume supported by dissolved-particulate exchange. Nat. Geosci. 10, 195-201 (2017). doi: 10.1038/ ngeo2900

63. T. Ohde, I. Dadou, Seasonal and annual variability of coastal sulphur plumes in the northern Benguela upwelling system. PLOS ONE 13, e0192140 (2018). doi: 10.1371/journal. pone.0192140; pmid: 29420587

64. A. D. Clarke, S. R. Owens, J. Zhou, An ultrafine sea-salt flux from breaking waves: Implications for cloud condensation nuclei in the remote marine atmosphere. J. Geophys. Res. D Atmospheres 111 (D6), D06202 (2006). doi: 10.1029/ 2005JD006565

65. B. Gantt, N. Meskhidze, The physical and chemical characteristics of marine primary organic aerosol: A review. Atmos. Chem. Phys. 13, 3979-3996 (2013). doi: 10.5194/ acp-13-3979-2013
66. K. A. Prather et al., Bringing the ocean into the laboratory to probe the chemical complexity of sea spray aerosol. Proc. Natl. Acad. Sci. U.S.A. 110, 7550-7555 (2013) doi: 10.1073/pnas.1300262110; pmid: 23620519

67. D. C. O'Dowd, G. De Leeuw, Marine aerosol production: a review of the current knowledge. Philos. Trans. R. Soc London Ser. A 365, 1753-1774 (2007). doi: 10.1098/ rsta.2007.2043

68. M. M. Coggon et al., Ship impacts on the marine atmosphere: Insights into the contribution of shipping emissions to the properties of marine aerosol and clouds. Atmos. Chem. Phys. 12, 8439-8458 (2012). doi: 10.5194/acp-12-8439-2012

69. G. Oberdörster, E. Oberdörster, J. Oberdörster, Nanotoxicology: An emerging discipline evolving from studies of ultrafine particles. Environ. Health Perspect. 113, 823-839 (2005). doi: 10.1289/ehp.7339; pmid: 16002369

70. Nanomaterial Fate and Speciation in the Enviornment (NanoFASE) (European Union); http://nanofase.eu/.

71. C. M. Rochman, Microplastics research-from sink to source. Science 360, 28-29 (2018). doi: 10.1126/science.aar7734; pmid: 29622640

72. K. L. Law, R. C. Thompson, Microplastics in the seas. Science 345, 144-145 (2014). doi: 10.1126/science.1254065; pmid: 25013051

73. L. C. M. Lebreton et al., River plastic emissions to the world's oceans. Nat. Commun. 8, 15611 (2017). doi: 10.1038/ ncomms15611; pmid: 28589961

74. K. Mattsson, L. A. Hansson, T. Cedervall, Nano-plastics in the aquatic environment. Environ. Sci. Process. Impacts 17 1712-1721 (2015). doi: 10.1039/C5EM00227C; pmid: 26337600

75. Y. Chae, D. Kim, S. W. Kim, Y.-J. An, Trophic transfer and individual impact of nano-sized polystyrene in a four-species freshwater food chain. Sci. Rep. 8, 284 (2018). doi: 10.1038/ s41598-017-18849-y: pmid: 29321604

76. J. Lelieveld, J. S. Evans, M. Fnais, D. Giannadaki, A. Pozzer, The contribution of outdoor air pollution sources to premature mortality on a global scale. Nature 525, 367-371 (2015). doi: 10.1038/nature15371; pmid: 26381985

77. M. Geiser, W. G. Kreyling, Deposition and biokinetics of inhaled nanoparticles. Part. Fibre Toxicol. 7, 2 (2010). doi: 10.1186/1743-8977-7-2; pmid: 20205860

78. M. R. Miller et al., Inhaled nanoparticles accumulate at sites of vascular disease. ACS Nano 11, 4542-4552 (2017). doi: 10.1021/acsnano.6b08551; pmid: 28443337

79. B. A. Maher et al., Magnetite pollution nanoparticles in the human brain. Proc. Natl. Acad. Sci. U.S.A. 113, 10797-10801 (2016). doi: 10.1073/pnas.1605941113; pmid: 27601646

80. Y. Yang et al., Nanoparticles in road dust from impervious urban surfaces: Distribution, identification, and environmental implications. Environ. Sci. Nano 3, 534-544 (2016). doi: 10.1039/C6EN00056H

81. Y. Liu, G. Zhou, K. Liu, Y. Cui, Design of complex nanomaterials for energy storage: Past success and future opportunity. Acc. Chem. Res. 50, 2895-2905 (2017). doi: 10.1021/acs.accounts.7b00450; pmid: 29206446

82. L. Pourzahedi et al., Life cycle considerations of nano-enabled agrochemicals: Are today's tools up to the task? Environ. Sci. Nano 5, 1057-1069 (2018). doi: 10.1039/C7EN01166K

83. P. Westerhoff, P. Alvarez, Q. Li, J. Gardea-Torresdey, J. Zimmerman, Overcoming implementation barriers for nanotechnology in drinking water treatment. Environ. Sci. Nano 3, 1241-1253 (2016). doi: 10.1039/C6EN00183A

84. N. P. Qafoku, in Advances in Agronomy, D. Sparks, Ed. (Elsevier, 2010), vol. 107, pp. 33-91.

85. N. P. Qafoku, in Advances in Agronomy, D. Sparks, Ed. (Elsevier, 2015), vol. 131, pp. 111-172.

86. S. R. Gislason et al., Direct evidence of the feedback between climate and weathering. Earth Planet. Sci. Lett. 277, 213-222 (2009) doi: 10.1016/j.epsl.2008.10.018

87. The Intergovernmental Panel on Climate Change (IPCC), "Climate Change 2014: Synthesis Report. Contribution of Working Groups I, II and III to the Fifth Assessment Report of the Intergovernmental Panel on Climate Change" (IPCC, Geneva, Switzerland, 2014).

88. E. S. Eiriksdottir, S. R. Gislason, E. H. Oelkers, Direct evidence of the feedback between climate and nutrient, major, and trace element transport to the oceans. Geochim. Cosmochim. Acta 166, 249-266 (2015). doi: 10.1016/ j.gca.2015.06.005

89. K. L. Plathe et al., The role of nanominerals and mineral nanoparticles in the transport of toxic trace metals: Field-flow fractionation and analytical TEM analyses after nanoparticle isolation and density separation. Geochim. Cosmochim. Acta 102, 213-225 (2013). doi: 10.1016/j.gca.2012.10.029

90. D. J. Lapworth, B. Stolpe, P. J. Williams, D. C. Gooddy, J. R. Lead, Characterization of suboxic groundwater colloids using a multi-method approach. Environ. Sci. Technol. 47, 2554-2561 (2013). doi: 10.1021/es3045778; pmid: 2340264

91. S. Wang, D. Bailey, K. Lindsay, J. K. Moore, M. Holland, Impact of sea ice on the marine iron cycle and phytoplankton productivity. Biogeosciences 11, 4713-4731 (2014). doi: 10.5194/bg-11-4713-2014

92. K. L. Smith Jr., A. D. Sherman, T. J. Shaw, J. Sprintall, Icebergs as unique Lagrangian ecosystems in polar seas. Annu. Rev. Mar. Sci. 5, 269-287 (2013). doi: 10.1146/ annurev-marine-121211-172317; pmid: 22809193

93. A. R. Lawter et al., Element mobilization and immobilization from carbonate rocks between $\mathrm{CO}_{2}$ storage reservoirs and the overlying aquifers during a potential $\mathrm{CO}_{2}$ leakage. Chemosphere 197, 399-410 (2018). doi: 10.1016/ j.chemosphere.2017.12.199; pmid: 29360595

94. E. S. Ilton, N. P. Qafoku, C. Liu, D. A. Moore, J. M. Zachara, Advective removal of intraparticle uranium from contaminated vadose zone sediments, Hanford, U.S. Environ. Sci. Technol. 42, 1565-1571 (2008). doi: 10.1021/es071113m; pmid: 18441804

95. S. B. Grant et al., Taking the "waste" out of "wastewater" for human water security and ecosystem sustainability. Science 337, 681-686 (2012). doi: 10.1126/science.1216852; pmid: 22879506

96. N. C. Mueller, B. Nowack, Exposure modeling of engineered nanoparticles in the environment. Environ. Sci. Technol. 42, 4447-4453 (2008). doi: 10.1021/es7029637; pmid: 18605569

97. B. Vriens et al., Quantification of element fluxes in wastewaters: A nationwide survey in Switzerland. Environ. Sci. Technol. 51. 10943-10953 (2017). doi: 10.1021/ acs.est.7b01731; pmid: 28671459

98. K. L. Garner, A. A. Keller, Emerging patterns for engineered nanomaterials in the environment: A review of fate and toxicity studies. J. Nanopart. Res. 16, 2503 (2014). doi: 10.1007/s11051-014-2503-2

99. N. J. Loman et al., Performance comparison of benchtop high-throughput sequencing platforms. Nat. Biotechnol. 30 434-439 (2012). doi: 10.1038/nbt.2198; pmid: 22522955

100. J. W. Metch, N. D. Burrows, C. J. Murphy, A. Pruden, P. J. Vikesland, Metagenomic analysis of microbial communities yields insight into impacts of nanoparticle design. Nat. Nanotechnol. 13, 253-259 (2018). doi: 10.1038/ s41565-017-0029-3; pmid: 29335567

101. P. A. Holden et al., Ecological nanotoxicology: Integrating nanomaterial hazard considerations across the subcellular, population, community, and ecosystems levels. Acc. Chem. Res. 46, 813-822 (2013). doi: 10.1021/ar300069t; pmid: 23039211

102. M. Baalousha et al., Outdoor urban nanomaterials: The emergence of a new, integrated, and critical field of study. Sci. Total Environ. 557-558, 740-753 (2016). doi: 10.1016/ j.scitotenv.2016.03.132; pmid: 27046139

103. C. O. Hendren, G. V. Lowry, J. M. Unrine, M. R. Wiesner, A functional assay-based strategy for nanomaterial risk forecasting. Sci. Total Environ. 536, 1029-1037 (2015). doi: 10.1016/j.scitotenv.2015.06.100; pmid: 26188653

104. N. K. Geitner et al., Size-based differential transport, uptake, and mass distribution of ceria $\left(\mathrm{CeO}_{2}\right)$ nanoparticles in wetland mesocosms. Environ. Sci. Technol. 52, 9768-9776 (2018). doi: 10.1021/acs.est.8b02040; pmid: 30067347

105. F. Laborda et al., Detection, characterization and quantification of inorganic engineered nanomaterials: A review of techniques and methodological approaches for the analysis of complex samples. Anal. Chim. Acta 904, 10-32 (2016). doi: 10.1016/j.aca.2015.11.008 pmid: 26724760

106. M. D. Montaño, J. W. Olesik, A. G. Barber, K. Challis, J. F. Ranville, Single particle ICP-MS: Advances toward routine analysis of nanomaterials. Anal. Bioanal. Chem. 408, 5053-5074 (2016). doi: 10.1007/s00216-016-9676-8; pmid: 27334719

107. A. Praetorius et al., Single-particle multi-element fingerprinting (spMEF) using inductively-coupled plasma time-of-flight mass spectrometry (ICP-TOFMS) to identify engineered nanoparticles against the elevated natural background in soils. Environ. Sci. Nano 4, 307-314 (2017). doi: 10.1039/C6EN00455E 
108. M. H. Nielsen, S. Aloni, J. J. De Yoreo, In situ TEM imaging of $\mathrm{CaCO}_{3}$ nucleation reveals coexistence of direct and indirect pathways. Science 345, 1158-1162 (2014). doi: 10.1126/ science.1254051; pmid: 25190792

109. H. Takahashi et al., Development of soft x-ray emission spectrometer for EPMA/SEM and its application. IOP Conf. Series Mater. Sci. Eng. 109, 012017 (2016). doi: 10.1088/ 1757-899X/109/1/012017

110. H. Takahashi, P. McSwiggen, C. Nielsen, A unique wavelengthdispersive soft $\mathrm{x}$-ray emission spectrometer for electron probe x-ray microanalyzers. Microsc. Anal. (Am. Ed.) 15, S5-S8 (2014).

111. D. Li et al.. Trends in mica-mica adhesion reflect the influence of molecular details on long-range dispersion forces underlying aggregation and coalignment. Proc. Natl. Acad. Sci. U.S.A. 114, 7537-7542 (2017). doi: 10.1073/ pnas.1621186114; pmid: 28679632

112. M. L. Sushko, K. M. Rosso, The origin of facet selectivity and alignment in anatase $\mathrm{TiO}_{2}$ nanoparticles in electrolyte solutions: Implications for oriented attachment in metal oxides. Nanoscale 8, 19714-19725 (2016). doi: 10.1039/ C6NR06953C; pmid: 27874139

113. X. Zhang et al., Direction-specific interaction forces underlying zinc oxide crystal growth by oriented attachment Nat. Commun. 8, 835 (2017). doi: 10.1038/s41467-01700844-6; pmid: 29018200

114. X. Zhang et al., Direction-specific van der Waals attraction between rutile $\mathrm{TiO}_{2}$ nanocrystals. Science $356,434-437$ (2017). doi: 10.1126/science.aah6902; pmid: 28450642

115. Z. Shen, J. Chun, K. M. Rosso, C. J. Mundy, Surface chemistry affects the efficacy of the hydration force between two ZnO (1010) surfaces. J. Phys. Chem. C 122, 12259-12266 (2018). doi: 10.1021/acs.jpcc.8b02421

116. A. A. May et al., Gas-and particle-phase primary emissions from in-use, on-road gasoline and diesel vehicles. Atmos. Environ. 88, 247-260 (2014). doi: 10.1016/ j.atmosenv.2014.01.046
117. British Petroleum (BP), BP energy outlook; www.bp.com/en/ global/corporate/energy-economics/energy-outlook.html [accessed 1 November 2018]

118. U. S. Energy Information Administration, Analysis and projections; www.eia.gov/analysis/ [accessed 1 November 2018].

119. H. Yi, J. Hao, L. Duan, X. Li, X. Guo, Characteristics of inhalable particulate matter concentration and size distribution from power plants in China. J. Air Waste Manag. Assoc. 56, 1243-1251 (2006). doi: 10.1080/ 10473289.2006.10464590; pmid: 17004679

120. Q. Ma et al., Impacts of coal burning on ambient $\mathrm{PM}_{25}$ pollution in China. Atmos. Chem. Phys. 17, 4477-4491 (2017). doi: 10.5194/acp-17-4477-2017

121. T. Makonese, D. M. Masekameni, H. J. Annegarn, P. B. C. Forbes, Emission factors of domestic coal-burning braziers. S. Afr. J. Sci. 113, 1-11 (2017). doi: 10.17159/ sajs.2017/20160187

122. M. Zetterdahl, J. Moldanová, X. Pei, R. K. Pathak, B. Demirdjian, Impact of the $0.1 \%$ fuel sulfur content limit in SECA on particle and gaseous emissions from marine vessels. Atmos. Environ. 145, 338-345 (2016). doi: 10.1016/ j.atmosenv.2016.09.022

123. L. Durdina et al., Assessment of particle pollution from jetliners: From smoke visibility to nanoparticle counting. Environ. Sci. Technol. 51, 3534-3541 (2017). doi: 10.1021/ acs.est.6b05801; pmid: 28230356

124. L. Corio, K. Olson, The need for alternate $\mathrm{PM}_{25}$ emission factors for gas-fired combustion units. Power 159, 51-54 (2015).

125. G. Scheffknecht, L. Al-Makhadmeh, U. Schnell, J. Maier, Oxy-fuel coal combustion-A review of the current state-ofthe-art. Int. J. Greenh. Gas Control 5, S16-S35 (2011). doi: 10.1016/j.jiggc.2011.05.020

126. D. R. Boverhof et al., Comparative assessment of nanomaterial definitions and safety evaluation considerations. Regul. Toxicol. Pharmacol. 73, 137-150

(2015). doi: 10.1016/j.yrtph.2015.06.001; pmid: 26111608

\section{ACKNOWLEDGMENTS}

We are indebted to R. Perry, scientific illustrator (PNNL): N. Wigginton, assistant vice president for research (University of Michigan), T. Pruitt, NanoEarth assistant director (Virginia Tech); and $\mathrm{M}$. Bruckner, science education and evaluation associate (Carleton College). Funding: We thank the U.S. National Science Foundation (NSF) for fully funding the 2018 NanoEarth Writing Workshop (EAR-1822111 to M.F.H.). The writing workshop was held at the Institute for Critical Technology of Applied Sciences at Virginia Tech, Blacksburg, Virginia, from 19 to 22 April 2018, where all authors assembled to write the first draft of this paper. This writing workshop was convened by NanoEarth (NSF ECCS-1542100 to M.F.H.) and MONT (NSF ECCS-1542210 to D.W.M.), both nodes within NSF's National Nanotechnology Coordinated Infrastructure (NNCl), and J.R. (Colorado School of Mines). M.F.H., L.C.M., and P.V. also acknowledge CEINT (NSF EF-0830093) and Virginia Tech's ICTAS-housed laboratories and instruments. G.W.L. acknowledges support from NSF Chemical Oceanography (OCE-1558738) and NSF Marine Geology and Geophysics (OCE-1558712). K.M.R. acknowledges support from the U.S. Department of Energy Office of Science, Office of Basic Energy Sciences Geosciences program. N.S. acknowledges support from NSF (EAR-1251479). P.A.S. acknowledges support from the NSF Critical Zone Observatory program (EAR-1331846). P.W. acknowledges support from NSF Nanosystems Engineering Research Center on NanotechnologyEnabled Water Treatment (EEC-1449500), the NSF NNCI node at ASU (NNCI - 1542160), and USEPA STAR grant (RD83558001) for the Life Cycle of Nanomaterials. Y.Y. acknowledges support from the National Natural Science Foundation of China (NNSFC 41522111). Competing interests: The authors declare no competing interests.

10.1126/science.aau8299 


\section{Science}

\section{Natural, incidental, and engineered nanomaterials and their impacts on the Earth system}

Michael F. Hochella Jr., David W. Mogk, James Ranville, Irving C. Allen, George W. Luther, Linsey C. Marr, B. Peter McGrail, Mitsu Murayama, Nikolla P. Qafoku, Kevin M. Rosso, Nita Sahai, Paul A. Schroeder, Peter Vikesland, Paul Westerhoff and Yi Yang

Science 363 (6434), eaau8299.

DOI: $10.1126 /$ science.aau8299

\section{Nanomaterials in the Earth system}

Nanomaterials have been part of the Earth system for billions of years, but human activities are changing the nature and amounts of these materials. Hochella Jr. et al. review sources and impacts of natural nanomaterials, which are not created directly through human actions; incidental nanomaterials, which form unintentionally during human activities; and engineered nanomaterials, which are created for specific applications. Knowledge of the properties of all three types as they cycle through the Earth system is essential for understanding and mitigating their long-term impacts on the environment and human health.

Science, this issue p. eaau8299

RELATED

CONTENT

REFERENCES

PERMISSIONS http://science.sciencemag.org/content/sci/363/6434/1390.ful http://science.sciencemag.org/content/sci/363/6434/1392.full http://science.sciencemag.org/content/sci/363/6434/1402.full file:/content

This article cites 115 articles, 16 of which you can access for free http://science.sciencemag.org/content/363/6434/eaau8299\#BIBL

http://www.sciencemag.org/help/reprints-and-permissions

Use of this article is subject to the Terms of Service

Science (print ISSN 0036-8075; online ISSN 1095-9203) is published by the American Association for the Advancement of Science, 1200 New York Avenue NW, Washington, DC 20005. 2017 (C) The Authors, some rights reserved; exclusive licensee American Association for the Advancement of Science. No claim to original U.S. Government Works. The title Science is a registered trademark of AAAS. 